\title{
Deletion Mutants of the Attenuated Recombinant ASF Virus, BA71 $\Delta C D 2$, Show Decreased Vaccine Efficacy
}

\author{
Elisabeth Lopez $^{1}{ }^{\mathbb{D}}$, Laia Bosch-Camós ${ }^{1}{ }^{\mathbb{D}}$, Elizabeth Ramirez-Medina ${ }^{2}$, Elizabeth Vuono ${ }^{2}$, Maria Jesus Navas ${ }^{1}$, \\ Marta Muñoz ${ }^{1}$, Francesc Accensi ${ }^{1,3}{ }^{\mathbb{D}}$, Jinya Zhang ${ }^{1}$, Uxia Alonso ${ }^{1}$, Jordi Argilaguet ${ }^{1}$, Maria Luisa Salas ${ }^{4}$, \\ Nikolay Anachkov ${ }^{5}$, Douglas P. Gladue ${ }^{2,+}\left(\mathbb{D}\right.$, Manuel V. Borca ${ }^{2,+}$, Sonia Pina-Pedrero ${ }^{1, *,+}$ (D) \\ and Fernando Rodriguez ${ }^{1, *,+(\mathbb{D})}$
}

check for updates

Citation: Lopez, E.; Bosch-Camós, L.; Ramirez-Medina, E.; Vuono, E.; Navas, M.J.; Muñoz, M.; Accensi, F.; Zhang, J.; Alonso, U.; Argilaguet, J.; et al. Deletion Mutants of the Attenuated Recombinant ASF Virus, BA71 $\triangle \mathrm{CD} 2$, Show Decreased Vaccine Efficacy. Viruses 2021, 13, 1678. https://doi.org/10.3390/v13091678

Academic Editors: Chao-Nan Lin and Peck Toung Ooi

Received: 13 July 2021

Accepted: 6 August 2021

Published: 25 August 2021

Publisher's Note: MDPI stays neutral with regard to jurisdictional claims in published maps and institutional affiliations.

Copyright: (c) 2021 by the authors. Licensee MDPI, Basel, Switzerland. This article is an open access article distributed under the terms and conditions of the Creative Commons Attribution (CC BY) license (https:// creativecommons.org/licenses/by/ $4.0 /)$.
1 IRTA, Centre de Recerca en Sanitat Animal (IRTA-CReSA), Campus de la Universitat Autonoma de Barcelona, 08193 Bellaterra, Spain; elisabeth.lopezf@gmail.com (E.L.); Laia.Bosch@irta.cat (L.B.-C.); mariajesus.navas@irta.cat (M.J.N.); Marta.munoz@irta.cat (M.M.); Francesc.accensi@irta.cat (F.A.); jinya.zhang@irta.cat (J.Z.); Uxia.alonso@irta.cat (U.A.); jordi.argilaguet@irta.cat (J.A.)

2 USDA Plum Island Animal Disease Center, Agricultural Research Service, United States Department of Agriculture, Greenport, NY 11944, USA; Elizabeth.Ramirez@usda.gov (E.R.-M.);

Elizabeth.Vuono@usda.gov (E.V.); Douglas.Gladue@usda.gov (D.P.G.); Manuel.Borca@usda.gov (M.V.B.)

3 Departament de Sanitat i d'Anatomia Animals, Facultat de Veterinària, UAB, 08193 Bellaterra, Spain

4 Centro de Biología Molecular Severo Ochoa, Consejo Superior de Investigaciones Científicas, Campus de la Universidad Autònoma de Madrid, 28049 Madrid, Spain; mlsalas@cbm.csic.es

5 Biologics Development, Huvepharma, 3A Nikolay Haytov Street, 1113 Sofia, Bulgaria; n_anachkov@biovet.com

* Correspondence: sonia.pina@irta.cat (S.P.-P.); Fernando.rodriguez@irta.cat (F.R.)

+ These authors contributed equally to this work.

Abstract: African swine fever (ASF) has become the major threat to the global swine industry. Lack of available commercial vaccines complicates the implementation of global control strategies. So far, only live attenuated ASF viruses (ASFV) have demonstrated solid protection efficacy at the experimental level. The implementation of molecular techniques has allowed the generation of a collection of deletion mutants lacking ASFV-specific virulence factors, some of them with promising potential as vaccine candidates against the pandemic genotype II ASFV strain currently circulating in Africa, Europe, Asia and Oceania. Despite promising results, there is room for improvement, mainly from the biosafety point of view. Aiming to improve the safety of BA71 $\triangle \mathrm{CD} 2$, a cross-protective recombinant live attenuated virus (LAV) lacking the ASFV CD2v gene (encoding $\beta$-glucuronidase as a reporter gene) available in our laboratory, three new recombinants were generated using BA71 $\triangle \mathrm{CD} 2$ as a template: the single mutant $\mathrm{BA} 71 \triangle \mathrm{CD} 2 f$, this time containing the fluorescent mCherry reporter gene instead of $C D 2 v$, and two double recombinants lacking CD2v and either the lectin gene (EP153R) or the uridine kinase (UK) gene (DP96R). Comparative in vivo experiments using BA71 $\triangle \mathrm{CD} 2 f$, $\mathrm{BA} 71 \triangle \mathrm{CD} 2 \mathrm{DP} 96 \mathrm{R}$ and BA71 $\triangle \mathrm{CD} 2 \mathrm{EP} 153 \mathrm{R}$ recombinant viruses as immunogens, demonstrated that deletion of either DP96R or EP153R from BA71 $\Delta C D 2 f$ decreases vaccine efficacy and does not improve safety. Our results additionally confirm ASFV challenge as the only available method today to evaluate the protective efficacy of any experimental vaccine. We believe that understanding the fine equilibrium between attenuation and inducing protection in vivo deserves further study and might contribute to more rational vaccine designs in the future.

Keywords: African swine fever (ASF); African swine fever virus (ASFV); live attenuated virus (LAV); vaccine; virulence factor; double mutant; protection

\section{Introduction}

Lack of commercially available vaccines complicates the control of African swine fever (ASF), today's number one threat to the global swine industry [1]. The complexity of African swine fever virus (ASFV), the causative agent of ASF, together with the limited 
resources historically invested in this disease, has delayed vaccine development. This situation has dramatically changed with the last re-entrance of the virus in Europe in 2007 and the subsequent spread to the West, reaching the European Union in 2014, and to the East, reaching China in 2018. It has been shown that classically inactivated vaccines for ASF are ineffective, independent of the adjuvant tested [2]. To date, all subunit vaccines that have been reported have failed at inducing solid protection against the pandemic ASFV (Georgia2007/1), despite being the ideal choice in the long term if one becomes available [3]. So far, only ASF live attenuated viruses (LAVs) have conferred solid protection against experimental challenge with homologous viruses, with both antibodies and $\mathrm{T}$ cells, playing important roles in the protection afforded $[4,5]$. These studies have been performed with either natural attenuated ASFV isolates or with recombinant LAVs obtained by specific deletions of virulence-associated genes from the homologous virulent virus [6-11]. Additionally, our previous studies have demonstrated the cross-protective ability of $\mathrm{BA} 71 \triangle \mathrm{CD} 2$, a deletion mutant lacking the $\mathrm{CD} 2 \mathrm{v}$ (encoding $\beta$-glucuronidase as a reporter gene) from the genotype I virulent BA71 ASFV strain, to confer protection against both parental BA71 and genotype II Georgia2007/1 experimental challenges [12]. Despite its protective potential and the ability to grow in stable cell cultures (Cos- 1 cells) without genetic changes, a small percentage of BA71 $\triangle C D 2$-immunized pigs showed low, but detectable, amounts of ASFV DNA in sera [12]. Aiming to reduce the residual viral load observed with BA71 $\triangle \mathrm{CD} 2$ and increase the safety of our vaccine prototype, three new recombinant viruses were generated using the same methodology and substituting the ASFV ORFs with fluorescent markers: the single mutant BA71 $\triangle C D 2 f$, this time containing the fluorescent mCherry marker instead of CD2v, and two double recombinants lacking CD2v and a second virulence-associated gene, either DP96R, encoding the ASFV uridine kinase gene [8], or EP153R, encoding the ASFV lectin [13]. Once generated, the two double mutants, BA71 $\triangle$ CD2DP96R and BA71 $\triangle$ CD2EP153R, were used in a comparative in vivo immunization study with their parental fluorescent counterpart, BA71 $\triangle \mathrm{CD} 2 f$, whereas the control group of the whole experiment was immunized with PBS. Finally, all pigs were challenged with the pandemic Georgia2007/1 strain. The specific antibody and T-cell responses induced, together with the presence of ASFV in pig sera before and after challenge, determined that the additional deletion of DP96R or EP153R from BA71 $\triangle$ CD2 $f$ did not improve the safety of the vaccine, but instead reduced the protective potential against Georgia2007/1 challenge. These studies confirm previous results obtained with other recombinant LAVs designed using genotype II and I ASFV strains as templates [14-18]. The lack of exact correlation between in vitro assays and protection in swine confirms ASFV challenge as the only valid method to accurately evaluate the protective efficacy of any experimental vaccine approach. Understanding the mechanisms governing the efficacy of LAVs might become essential to design safer vaccine approaches against ASF in the future.

\section{Methods}

\subsection{Cells and Viruses}

Porcine alveolar macrophages (PAMs) were obtained by successive bronchoalveolar lung lavages with PBS. Macrophage cell culture was performed with RPMI 1640 medium (Life Technologies, Grand Island, NY, USA), supplemented with $10 \%$ fetal bovine serum (HyClone, GE Healthcare, Chicago, IL, USA).

The recombinant viruses were purified by limited dilution on PAMs. The virulent isolate Georgia2007/1, used for challenge purposes, was kindly provided by Dr. Linda Dixon (The Pirbright Institute, Ash Road, Pirbright, Surrey GU24 0NF, UK) and titrated in porcine macrophages.

\subsection{Generation of the Recombinant Deletion Mutants and Comparative In Vitro Growth Curves}

For comparative purposes, we first generated a fluorescent BA71 $\triangle \mathrm{CD} 2 f$ by homologous recombination (Figure 1A), following a similar procedure described before [19]. The right and left genome arms of the CD2 locus (approximately 700-800 bp in length) were 
obtained by DNA synthesis at Epoch Life Sciences (Sugar Land, TX, USA) to construct the p $72 \mathrm{mCherry} \triangle \mathrm{CD} 2$ transfer vector encoding the mCherry reporter gene under the ASFV p72 late promotor. Macrophage cell cultures were infected with the parental virus BA71 $\triangle \mathrm{CD} 2$ (containing a $\beta$-glucuronidase, encoded by the GusA gene, as a reporter gene) and transfected with the $\mathrm{p} 72 \mathrm{mCherry} \Delta \mathrm{CD} 2$ recombination transfer vector. By homologous recombination, the GusA gene was exchanged by the mCherry reporter gene, generating the recombinant $\mathrm{BA} 71 \triangle \mathrm{CD} 2 f$.

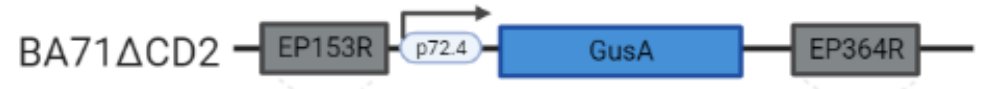

A

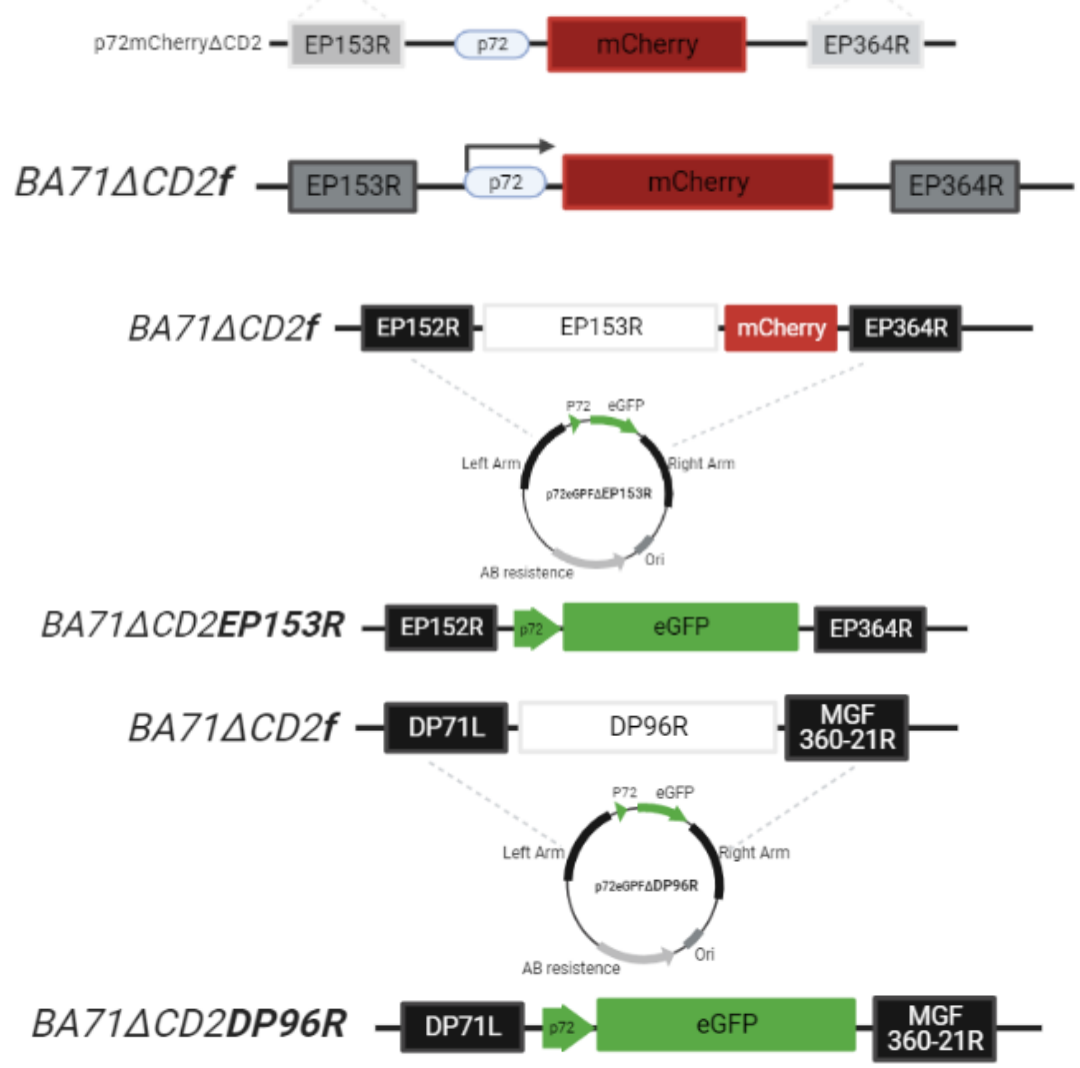

Figure 1. Schematic representation of the recombinant parental virus BA71 $\triangle \mathrm{CD} 2 f(\mathbf{A})$ and the EP153R and DP96R gene regions deleted by homologous recombination in recombinant viruses BA71 $\triangle \mathrm{CD} 2 E P 153 R$ and BA71 $\triangle \mathrm{CD} 2 \mathrm{DP} 96 \mathrm{R}(\mathrm{B})$. Dotted lines indicate the homologous regions between the parental virus and the correspondent transfer plasmid.

Next, we generated the recombinants BA71 $\triangle$ CD2DP96R and BA71 $\triangle C D 2 E P 153 R$, using BA71 $\triangle \mathrm{CD} 2 f$ as the parental virus and p72eGFP $\triangle \mathrm{DP} 96 \mathrm{R}$ or $\mathrm{p} 72 \mathrm{eGFP} \Delta \mathrm{EP} 153 \mathrm{R}$ as transfer vectors, respectively (Figure $1 \mathrm{~B})$. Both transfer vectors harbor the green fluorescent protein (eGFP) gene under the control of the ASFV p72 late gene promoter as a reporter gene cassette, flanked by the left and right homologous arms of the deleted ORFs to allow homologous recombination, following the same system described above.

The recombinant viruses were obtained after successive rounds of limit dilution purification on macrophage cell cultures, followed by a full genome sequencing to ensure the genome integrity and the designed deletions.

Comparative in vitro growth curves of BA71 $\triangle \mathrm{CD} 2 f, \mathrm{BA} 71 \triangle \mathrm{CD} 2 \mathrm{DP} 96 \mathrm{R}$ and BA71 $\triangle$ CD2EP153R were performed by infecting PAMs at a multiplicity of infection (MOI) of 0.1 . After $2 \mathrm{~h}$ of adsorption at $37^{\circ} \mathrm{C}$ in $5 \% \mathrm{CO}_{2}$, the inocula were removed and replaced with fresh media. The supernatants were harvested at 16, 24 and $48 \mathrm{~h}$ post infection (hpi). Virus loads in supernatants were quantified by qPCR following previously described 
methods [20] and the percentage of infected cells at each time point was followed by flow cytometry, detecting the eGFP or mCherry reporter genes.

\subsection{Animals, Hosting and Welfare}

Six-to-eight-week-old male (Large White $\times$ Landrace) pigs, ranging from 15 to $30 \mathrm{~kg}$, were housed in the BSL-3 facilities of Institut de Recerca i Tecnologia Agroalimentària (IRTA)-CReSA (Bellaterra, Spain). Animal experiments were conducted according to animal welfare ethics and protocols approved by the Ethics Commission in Animal Experimentation of the Generalitat de Catalunya (code CEA-OH/9212/2, in accordance to the European (Directive 2010/63/EU) and Spanish (Real Decreto 53/2013) regulations under the supervision of the IRTA's Ethical and Animal Welfare Committee.

\subsection{In Vivo Experimental Approach}

Twenty-four pigs were divided into four groups of six pigs each, without any contact between the groups. After one week of acclimation, each pig was intramuscularly immunized once with $1 \mathrm{~mL}$ of either PBS (control) or $10^{6}$ plaque-forming units (PFU) of either BA71 $\triangle \mathrm{CD} 2 f$, BA71 $\triangle \mathrm{CD} 2 \mathrm{EP} 153 \mathrm{R}$ or BA71 $\triangle \mathrm{CD} 2 \mathrm{DP96R}$.

Twenty-four days later, all pigs were intramuscularly challenged with $10^{3}$ gene equivalent copies (GEC) of the Georgia2007 / 1 ASFV virulent strain, equivalent to $10^{3}$ hemadsorbing units (HAU). Pigs were bled at days $0,4,7,14$ and 24 after immunization (dpi) and after Georgia2007/1 challenge (dpc) to follow both the kinetics of virus load by qPCR and the ASFV-specific antibody and T-cell responses. Rectal temperature and clinical signs were recorded daily, following guides previously published [21]. Post-mortem examinations were carried out to confirm or discard the presence of ASF-compatible pathological lesions.

\subsection{Analytical Methods}

Experimental immunization, clinical observations, immunological assays and virus titration methods were previously described $[12,21]$ and performed as briefly described below.

\subsubsection{Antibody Detection by ELISA}

Antibodies in pig sera were quantified by the OIE-approved indirect ELISA, based on soluble ASFV-infected cell-extract-coated plates, generously provided by Dr. Carmina Gallardo (EU ASF reference laboratory, CISA-INIA, Madrid, Spain). The presence of positive sera was detected using a peroxidase-conjugated anti-pig immunoglobulin $G$ (IgG) at 1:20,000 dilution (Sigma-Aldrich, St. Louis, MO, USA) as secondary antibody and soluble 3,3',5,5'-tetramethylbenzidine (TMB) as specific peroxidase substrate (SigmaAldrich). Reactions were stopped with $1 \mathrm{~N} \mathrm{H}_{2} \mathrm{SO}_{4}$ (Sigma-Aldrich), and the ELISA plates were read at an optical density of $450 \mathrm{~nm}\left(\mathrm{OD}_{450}\right)$.

\subsubsection{T-Cell Response by ELISPOT Assay}

The frequency of ASFV-specific interferon gamma-secreting cells (IFN $\gamma$-SC) in peripheral blood mononuclear cells (PBMCs) was analyzed by an enzyme-linked immunosorbent spot (ELISPOT) assay using commercial monoclonal antibody tandems (swine IFN $\gamma$; Cytoset). Briefly, PBMCs were isolated from whole blood by density-gradient centrifugation with Histopaque 1077 (Sigma-Aldrich). For PBMC cultures, RPMI 1640 medium supplemented with $10 \%$ fetal bovine serum (HyClone, GE HealthCare), 50,000 IU penicillin/L (Invitrogen), and $50 \mathrm{mg}$ streptomycin/L (Invitrogen) was used. Trypan blue was used to assess cell viability. PBMCs were specifically stimulated for $20 \mathrm{~h}$ in vitro with different ASFV isolates at a MOI of 0.2. RPMI, and $10 \mu \mathrm{g} / \mathrm{mL}$ of phytohemaglutinin (PHA, Sigma-Aldrich) was used as the control of the technique. Any sample scoring $\geq 300$ spots/500,000 PBMCs received a score of 300, which was considered the limit of our assay resolution. 


\subsubsection{Virus Quantification}

Titrating ASFV by hemadsorption is not always possible when working with nonhemadsorbing strains, such as BA71 $\triangle \mathrm{CD} 2$. Aiming to adopt a reliable comparative method for ASFV titration of multiple samples, pig sera, collected at different time points during the experiment, were used to quantify the ASFV virus DNA by real-time qPCR [20]. Due to the fact that our qPCR technique had previously shown more reproducible results in sera than in whole blood, virus in sera and no viremia was measured, being aware that the amount of virus present in blood after challenge with Georgia2007/1 would be around $1 \log$ higher in magnitude. Briefly, the viral genomic DNA was obtained from $200 \mu \mathrm{L}$ of sera using the Nucleospin Blood kit (Macherey-Nagel, Düren, Germany) and then used as template to amplify an 85 bp-long fragment from the ASFV serine protein kinase gene (R298L). PCR amplifications were performed in duplicate using the corresponding standards for absolute quantification. Results are expressed as $\log 10 \mathrm{GEC}$ per $\mathrm{mL}$ of sera. The detection limit of the technique was set at $10^{3} \mathrm{GEC} / \mathrm{mL}$.

\section{Results and Discussion}

\subsection{Replication of Recombinant Viruses in Swine Macrophage Cultures}

PAMs infected with either BA71 $\triangle C D 2 f$ and BA71 $\triangle C D 2 E P 153 R$ followed indistinguishable kinetics of infection (Figure 2). As expected, more than $95 \%$ of the PAMs were infected by $72 \mathrm{~h}$ (hpi) (Figure 2A), showing also similar maximum titers of ASFV-DNA in their supernatant (Figure 2B). Conversely, at the same multiplicity of infection (MOI), BA71 $\triangle$ CD2DP96R showed a delay in the infection kinetics, with only half of the PAMs becoming infected at $72 \mathrm{hpi}$ and showing a maximum titer one log below of those achieved by BA71 $\triangle \mathrm{CD} 2 f$ and BA71 $\triangle \mathrm{CD} 2 \mathrm{EP} 153 \mathrm{R}$.
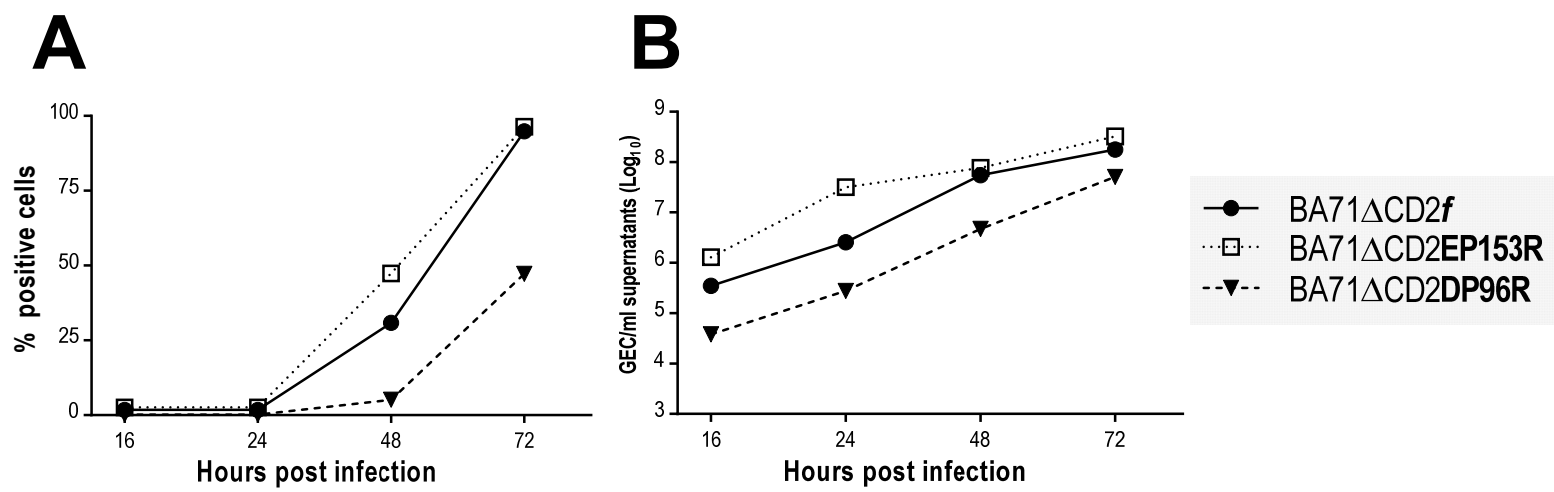

Figure 2. Comparative infection kinetics of the three recombinant viruses, BA71 $\triangle \mathrm{CD} 2 f, \mathrm{BA} 71 \triangle \mathrm{CD} 2 \mathrm{EP} 153 \mathrm{R}$ and BA71 $\triangle$ CD2DP96R, in PAMs. (A) Percentage of infected cells analyzed by flow cytometry and (B) ASFV DNA amount found in the supernatant of infected PAMs at different time points after infection.

\subsection{Comparative Protective Efficacy Induced by BA71 $\triangle C D 2 E P 153 R$ and BA71 $\triangle C D 2 D P 96 R$ Recombinant Viruses}

Aiming to confirm if the deletion of DP96R or EP153R reduced the residual viral load previously observed after immunization with BA71 $\triangle$ CD2 [12], the amount of ASFV DNA of each recombinant virus was followed directly after inoculation until the day of the Georgia2007/1 challenge (Figure 3). No clinical signs were observed following the immunization. The virus titers of BA71 $\triangle \mathrm{CD} 2 f$-immunized animals before challenge, as well as the protection afforded, yielded similar results to our previous studies [12], with the exception of pig number 66, euthanized at 6dpc (Figure 5), which responded poorly to the vaccine (Figures 7A and 8) and was Unfortunately, two out of the six pigs immunized with either BA71 $\triangle$ CD2EP153R or BA71 $\triangle$ CD2DP96R showed low albeit detectable copy numbers of virus genome in sera, confirming that these new prototypes do not improve the safety of BA71 $\triangle \mathrm{CD} 2$. 


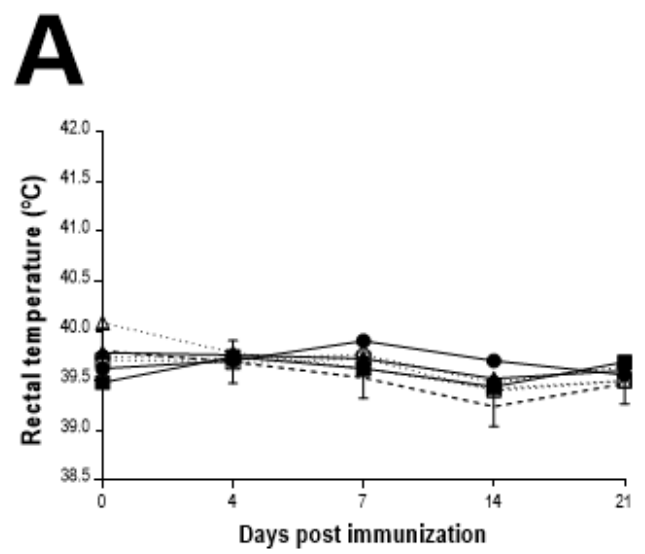

B
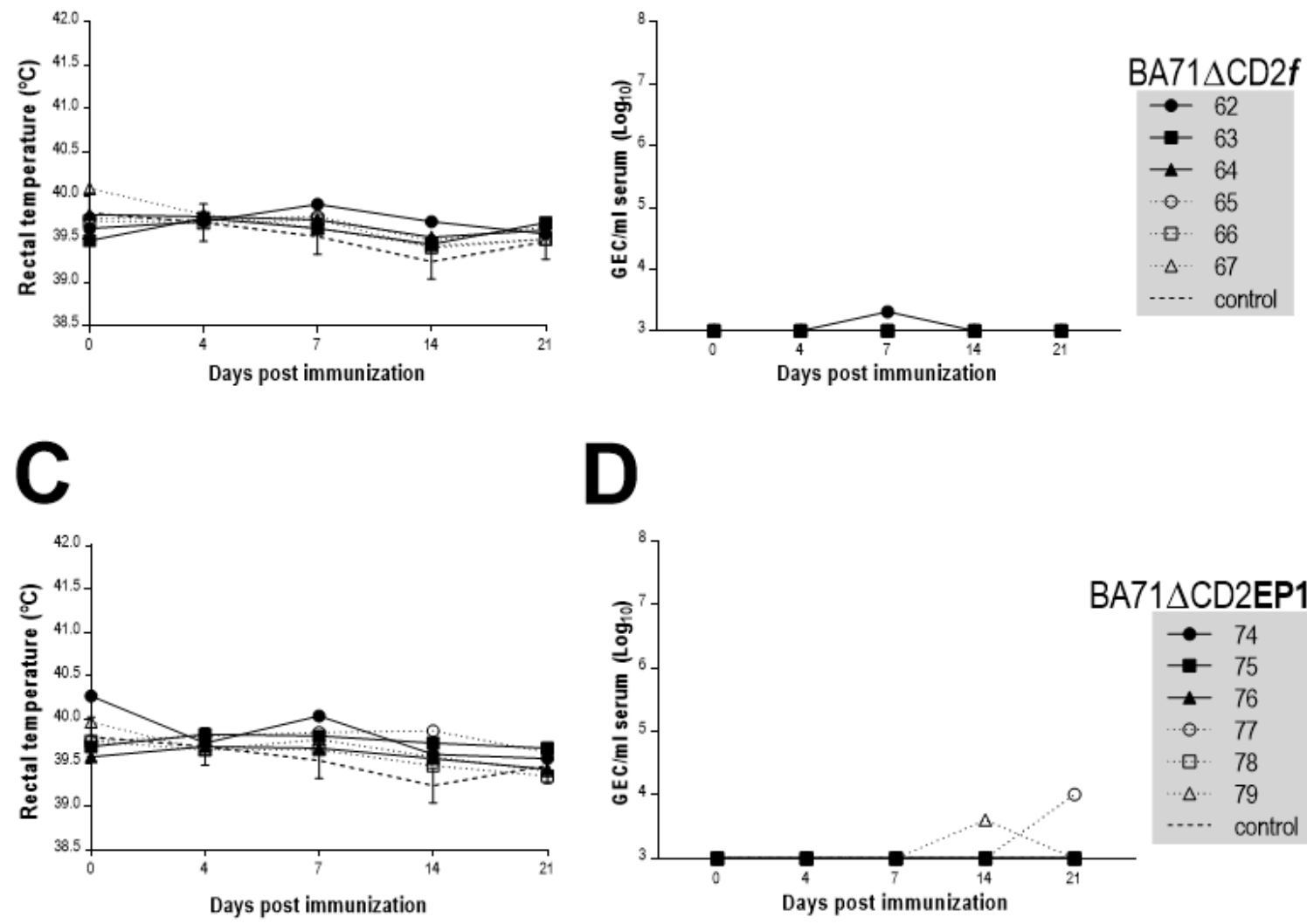

\section{D}
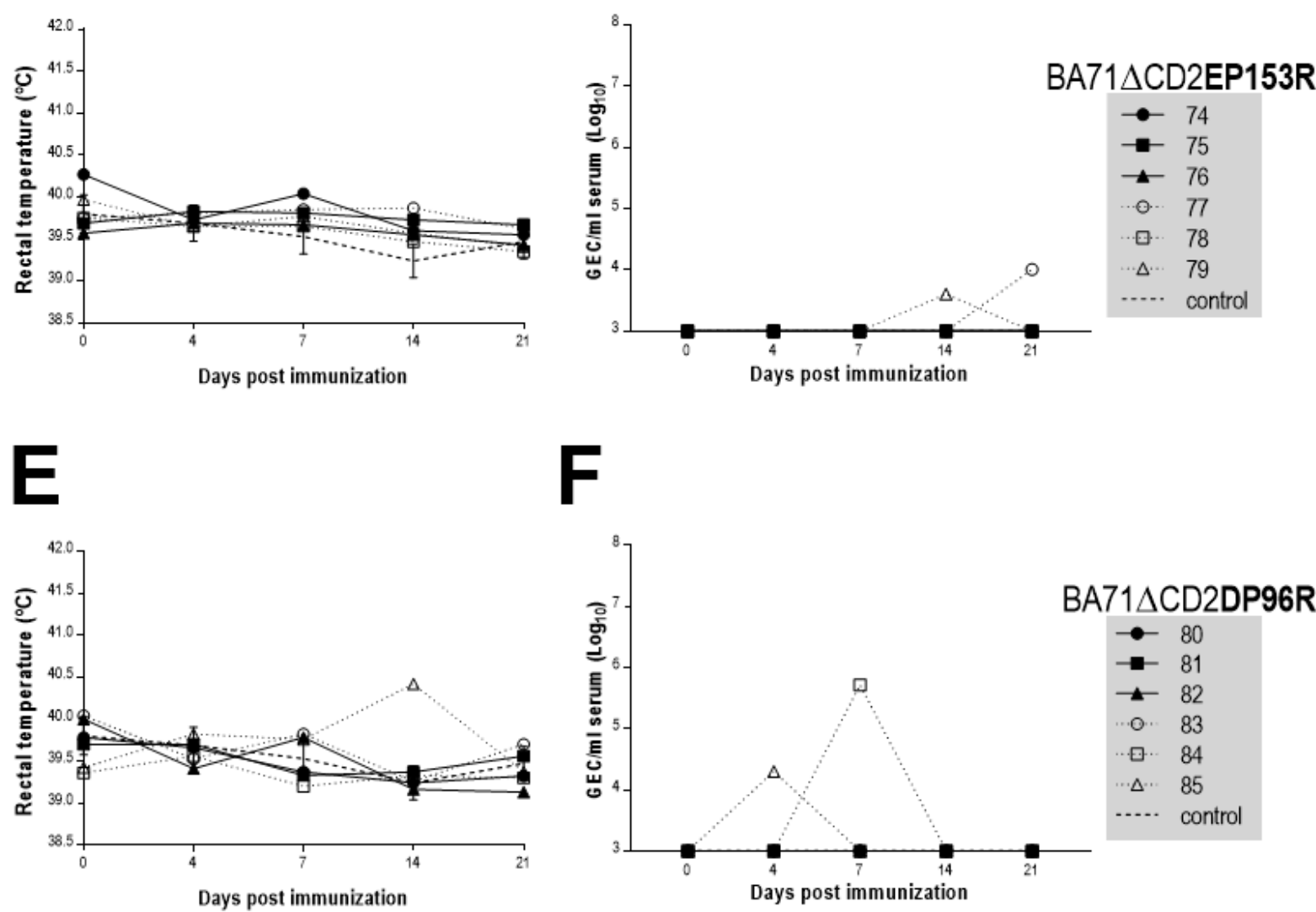

\section{$\mathbf{F}$}

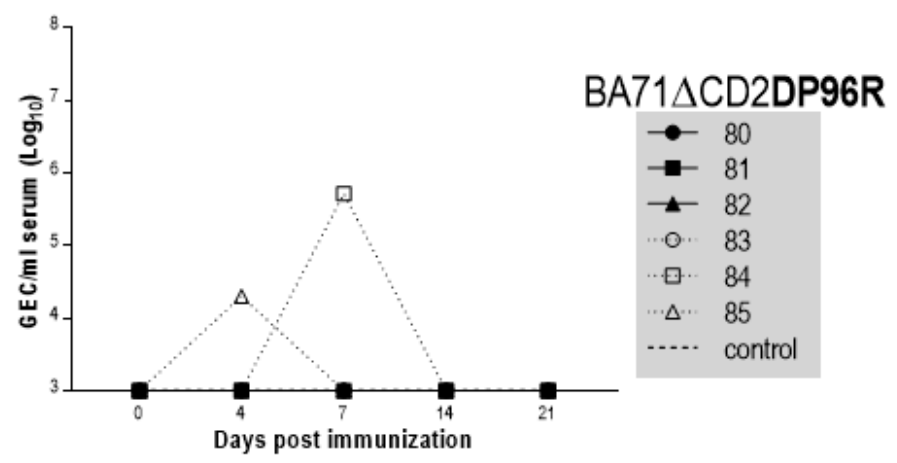

Figure 3. Rectal temperature and ASFV DNA amount found in sera after immunization with BA71 $\triangle \mathrm{CD} 2 f(\mathbf{A}, \mathbf{B})$ BA71 $\triangle$ CD2EP153R $(C, D)$ or BA71 $\triangle$ CD2DP96R $(E, F)$ in each individual animal. Average and standard deviation values from control pigs immunized with PBS are shown. ASFV DNA amounts are plotted on a logarithmic scale as GEC per milliliter of serum, $10^{3} \mathrm{GEC} / \mathrm{mL}$ being the limit of detection of the assay.

Twenty-four days after immunization, all pigs were intramuscularly challenged with a lethal dose of $10^{3}$ GEC of the highly pathogenic Georgia2007/1 isolate.

Control pigs were euthanized by day 8 post-challenge, while only one out of the six pigs vaccinated with BA71 $\triangle$ CD2 $f$ (animal 66) died after Georgia2007/1 challenge (Figure 4). One and two out of the six pigs inoculated with BA71 $\triangle$ CD2DP96R and BA71 $\triangle C D 2 E P 153 R$, respectively, did not survive the lethal ASFV challenge (Figure 4). 

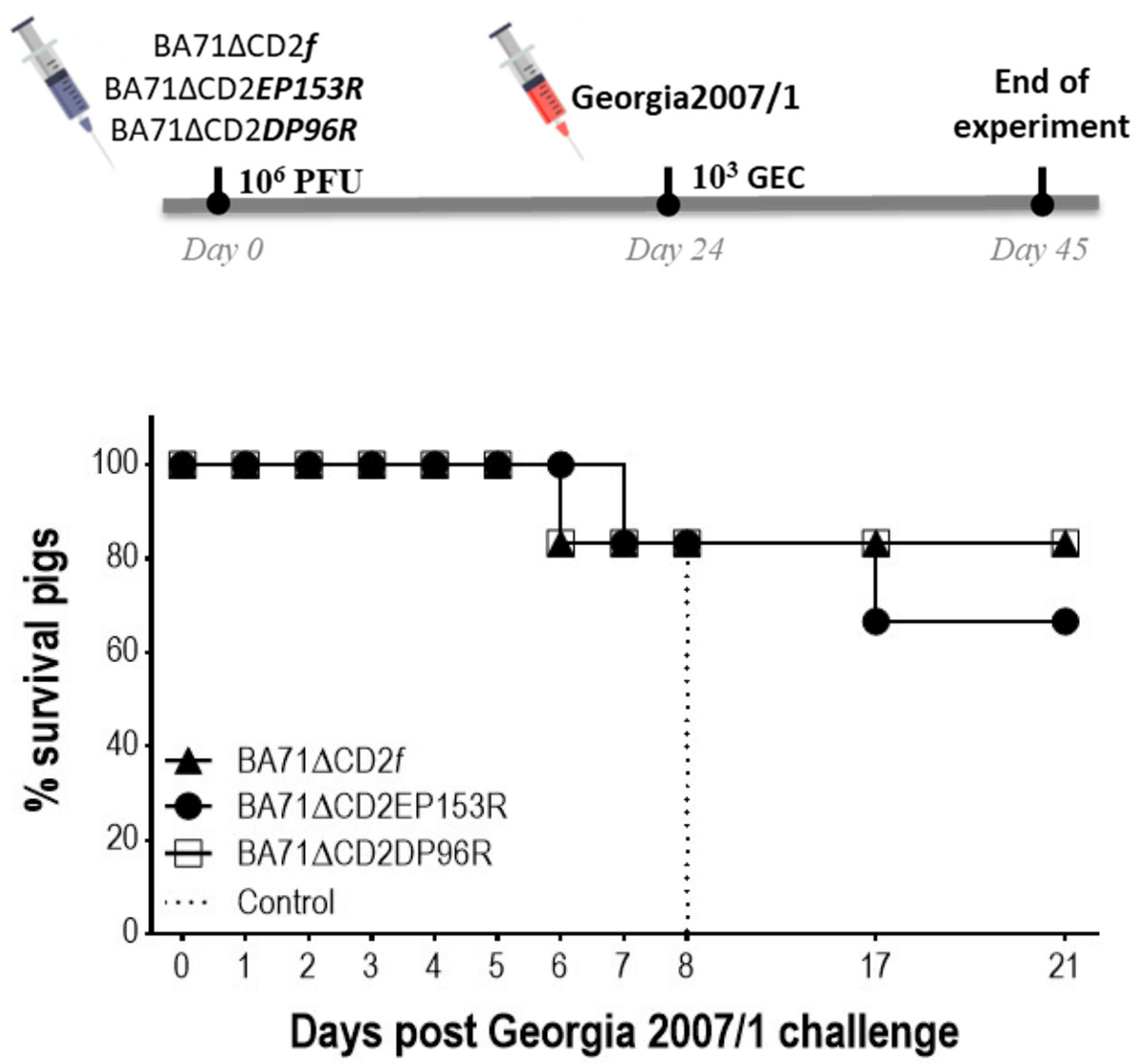

Figure 4. Survival rates after Georgia2007/1 challenge. Pigs were immunized with either BA71 $\Delta C D 2 f$, BA71 $\triangle \mathrm{CD} 2 \mathrm{DP} 96 \mathrm{R}$ or BA71 $\triangle \mathrm{CD} 2 \mathrm{EP} 153 \mathrm{R}$ and then challenged 24 days later with a lethal dose of Georgia 2007/1.

Pigs that succumbed to Georgia2007/1 challenge (six controls and four immunized with recombinant LAVs) showed clinical signs compatible with acute ASF (Figure 5), including fever, loss of appetite, depression, apathy and a tendency to huddling, as well as erythema and cyanosis. Conversely, surviving pigs did not show severe clinical signs after ASFV challenge (Figure 5). Three out of the six pigs immunized with BA71 $\triangle C D 2 f$ remained clinically normal, while the other two showed only a transient rise in rectal temperature. Thus, pig number 63 showed febricula $\left(\sim 40^{\circ} \mathrm{C}\right)$ from day 8 to $14 \mathrm{pc}$, while pig number 62 had fever only at day 8 post challenge (rectal temperature $<40.5^{\circ} \mathrm{C}$ ).

Furthermore, the clinical signs observed after Georgia2007/1 challenge were more evident and prolonged in pigs vaccinated with the double recombinants than with BA71 $\triangle C D 2 f$ (Figure 5), albeit that one out of the six pigs inoculated with BA71 $\triangle$ CD2EP153R (pig number 77) or BA71 $\triangle$ CD2DP96R (pig number 84) never showed any clinical signs. 
Days post Georgia2007/1 challenge

\begin{tabular}{|l|l|l|l|l|l|l|l|l|l|l|l|l|l|l|l|l|l|l|l|l|}
\hline 1 & 2 & 3 & 4 & 5 & 6 & 7 & 8 & 9 & 10 & 11 & 12 & 13 & 14 & 15 & 16 & 17 & 18 & 19 & 20 & 21 \\
\hline
\end{tabular}

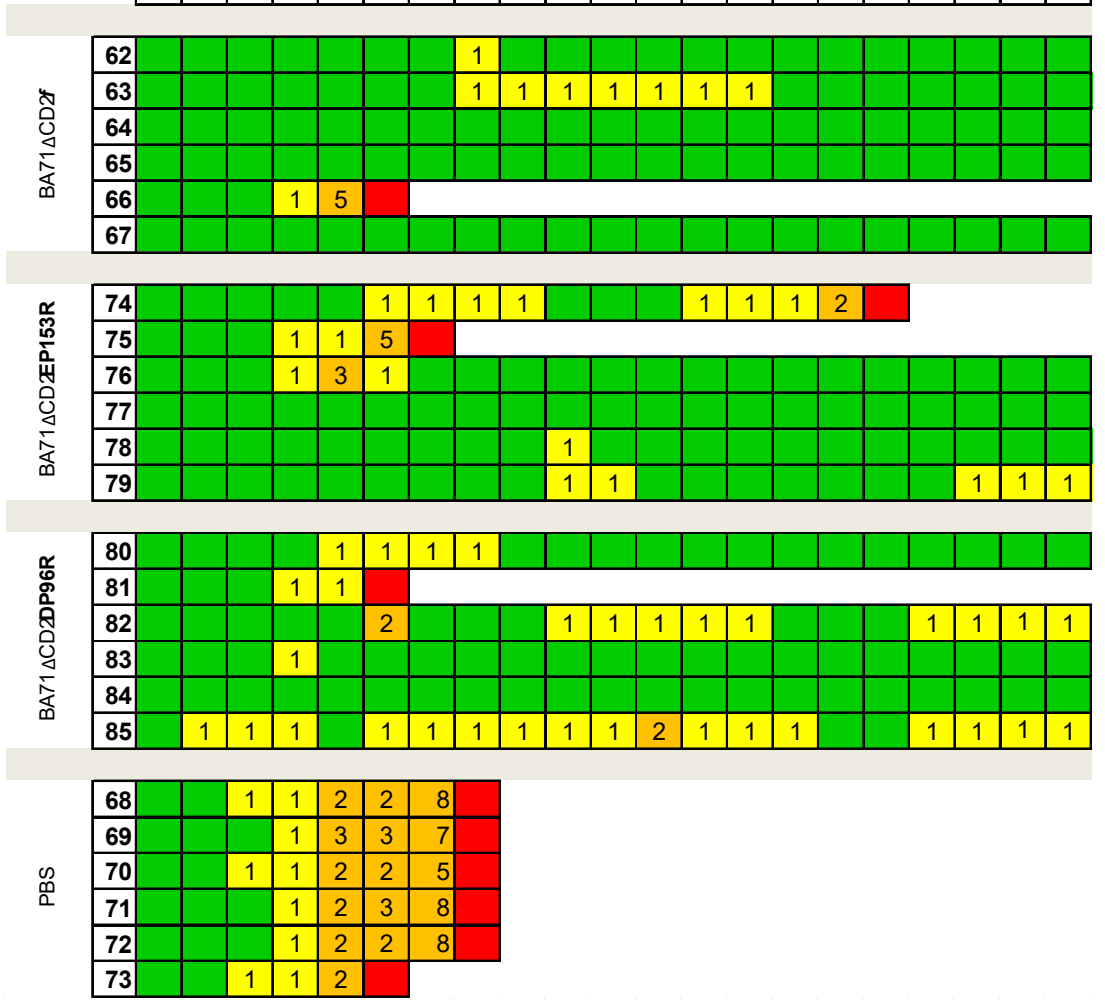

Figure 5. ASF compatible clinical signs observed after challenge. Color palette indicates normal (green), mild (yellow) and high $\left(>41^{\circ} \mathrm{C}\right.$; orange) rectal temperature, while euthanized animals are indicated in red. Clinical scores are indicated with numbers; 1 being low-grade fever $\left(<41^{\circ} \mathrm{C}\right)$ as the only clinical observation.

Rectal temperature almost perfectly matched the amount of ASFV DNA detected in serum (Figure 6) after challenge. All control pigs immunized with PBS were euthanized by day 6-8 after the lethal challenge showing significant fever and high amounts of ASFV DNA in sera. As expected, surviving pigs showed significantly lower amounts of ASFV DNA than control pigs (Figure 6). The massive release of immature and defective ASFV particles from lysed infected macrophages at the last stage of the ASFV infection, before the death of the animals, explains the non-linear correlation between GECs $\left(10^{10} \mathrm{GEC} / \mathrm{mL}\right)$ and HAU $\left(\sim 10^{8} \mathrm{HAU} / \mathrm{mL}\right)$ in these samples (not shown). Independently of this, the level of virus in sera of surviving pigs vaccinated with BA71 $\Delta$ CD2 $f$ (Figure $6 \mathrm{~A}, \mathrm{~B}$ ) was always 4-5 logarithms below that found in control animals. Furthermore, ASFV presence never lasted more than one week, becoming free of virus by the time of sacrifice, with pig number 65 not showing any detectable ASFV genome in its serum throughout the experiment. The level of virus in sera from pigs immunized with either BA71 $\triangle$ CD2EP153R (Figure 6C,D) or BA71 $\triangle$ CD2DP96R (Figure 6E,F) was also remarkably decreased compared to control animals. Nevertheless, the reduction in virus titers in sera from these animals was slightly lower than that found in the animals immunized with the single mutant BA71 $\triangle C D 2 f$, and several pigs showed detectable virus by the end of the experiment. 

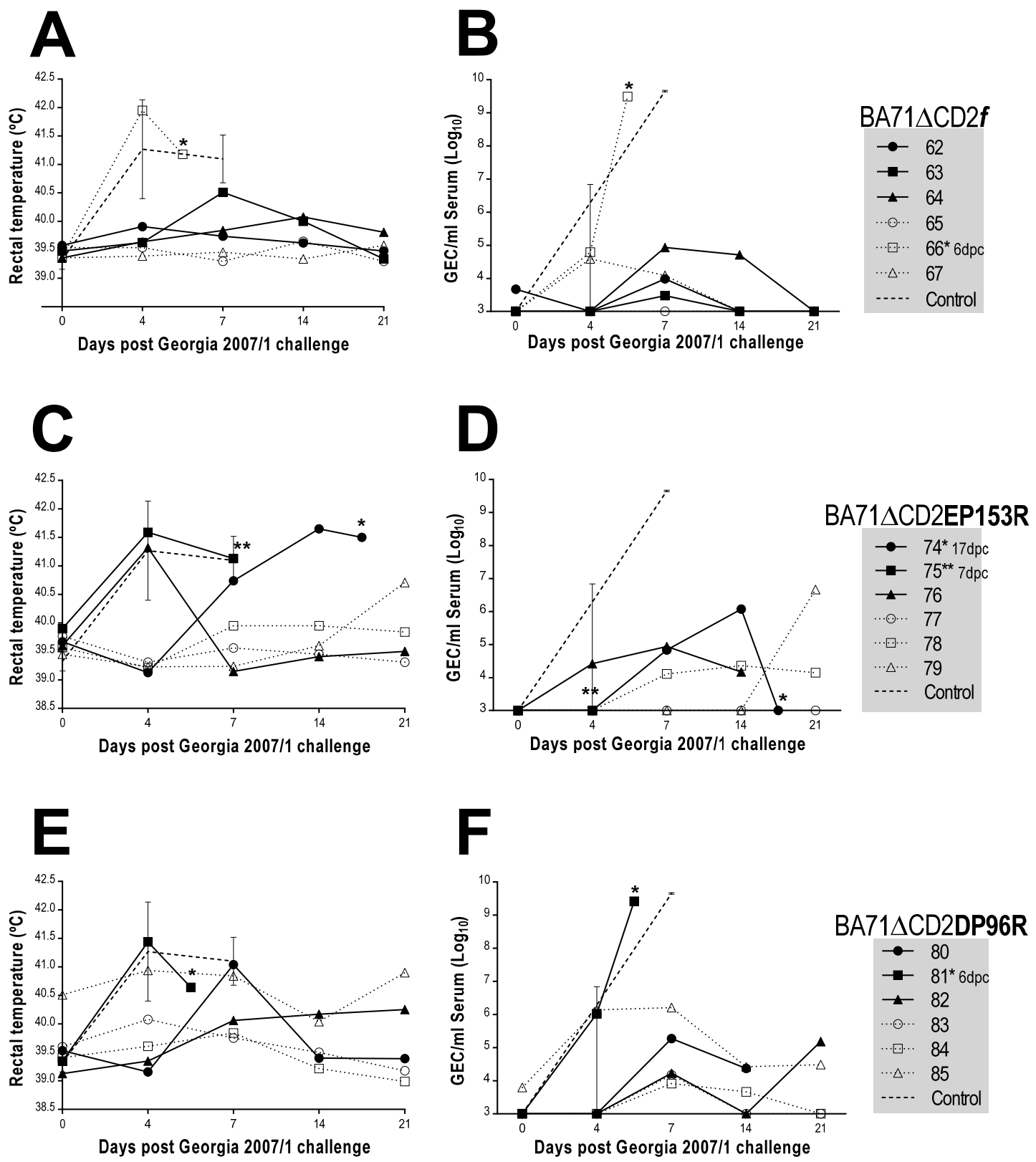

Figure 6. Rectal temperatures measured and ASFV DNA amount found in sera of immunized and control pigs after Georgia2007/1 challenge. Data plotted correspond to individual animals showing rectal temperatures (A,C,E) and virus loads in serum $(\mathbf{B}, \mathbf{D}, \mathbf{F})$. Upper panels show data corresponding to BA71 $\triangle \mathrm{CD} 2 f$ immunized pigs, middle panels to BA71 $\triangle \mathrm{CD} 2 \mathrm{EP} 153 \mathrm{R}$ and lower panels to BA71 $\triangle$ CD2DP96R. Average and standard deviation values obtained from control animals are also depicted. Virus titers are plotted on a logarithmic scale as GEC per milliliter of serum, $10^{3} \mathrm{GEC} / \mathrm{mL}$ serum being the limit of detection of the assay. * Day of the death of the animals. Last data recorded for pig 75 correspond to day 6pc (death date).

\subsection{Evaluation of the Immune Response Induced by BA71 $\triangle C D 2 E P 153 R$ and $B A 71 \triangle C D 2 D P 96 R$}

The antibody kinetics observed before and after challenge were as expected for both controls and BA71 $\triangle \mathrm{CD} 2 f$ immunized pigs [12], with the only exception being pig number 66, which showed significant lower ODs than the rest of the animals within the group (Figure 7A). The fact that this pig also showed the lowest ASFV-specific T-cell response (Figure 8) may suggest the possibility of a human/mechanical failure during vaccination, although a simple vaccine failure cannot be ruled out. The severity of the clinical signs observed after challenge (highest score of 12 recorded by day 6 , forcing a humane endpoint) might be explained by either an exacerbation effect due to suboptimal immunization 
as has been described before [2,22] and/or some concomitant health affection. Despite the importance of the ELISA as an indicator of successful immunization, there is not a total correlation between the level of ASFV-specific antibodies measured by ELISA and protection. Thus, pigs 74 and 75 immunized with BA71 $\triangle$ CD2EP153R and pig 81 immunized with BA71 $\triangle$ CD2DP96R died after challenge, despite showing similar antibody levels to surviving pigs at the time of Georgia2007/1 challenge. Conversely, pigs 80 and 82 survived the lethal challenge, despite showing slightly lower ODs.

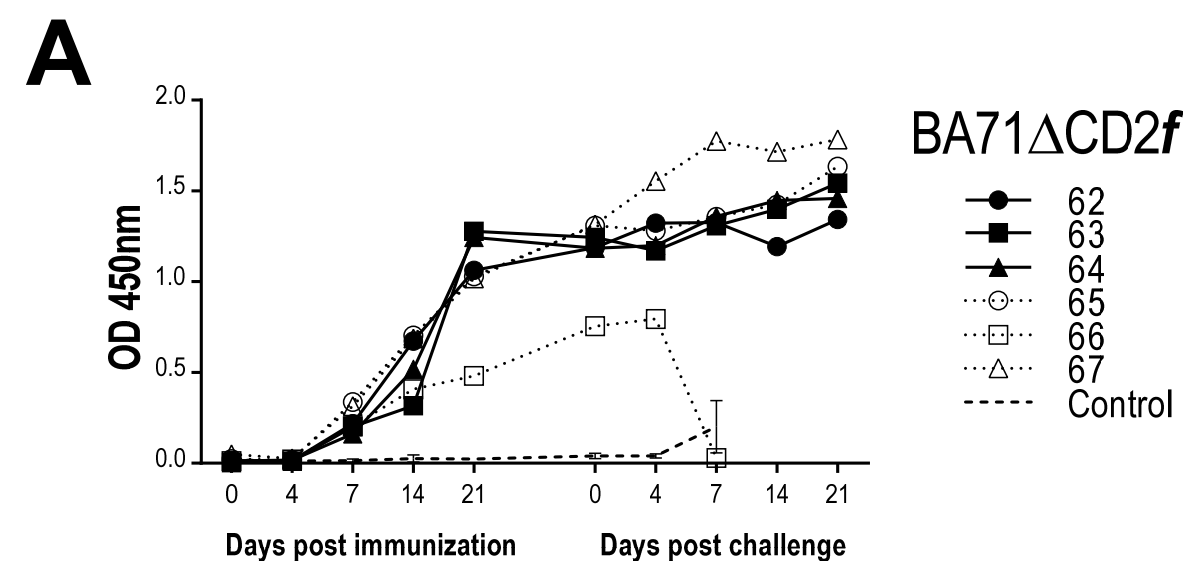

B

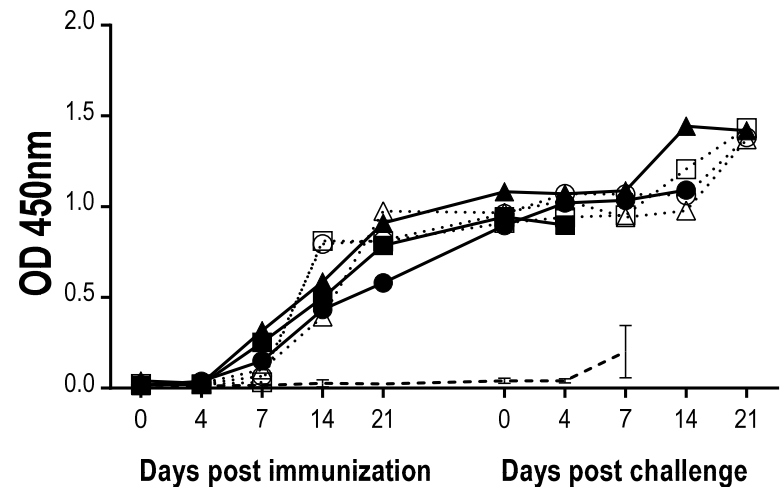

$\mathrm{BA} 71 \triangle \mathrm{CD} 2 \mathrm{EP} 153 \mathrm{R}$

$\rightarrow 74$

$\rightarrow-75$

$\rightarrow 76$

… 78

$\cdots \Delta \cdots 79$

....- Control

C

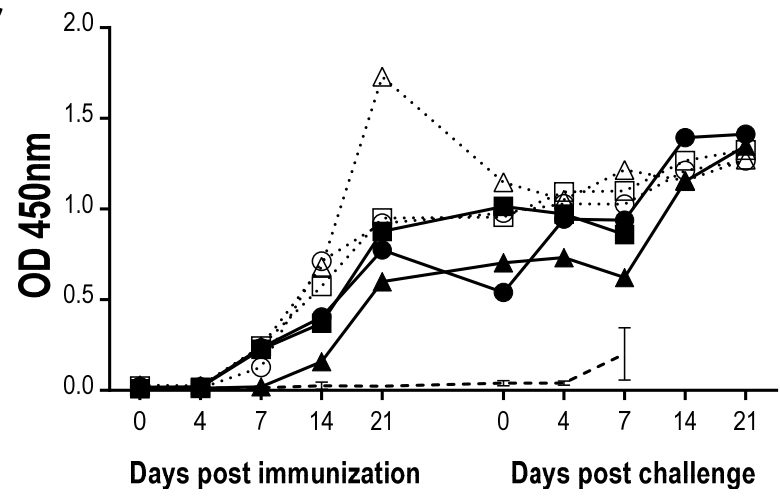

$\mathrm{BA71} \triangle \mathrm{CD} 2 \mathrm{DP96R}$

$\because 80$

$\rightarrow-81$

…… 83

$\cdots \boxminus \cdots \quad 84$

$\cdots \Delta \cdots \quad 85$

.... Control

Figure 7. ASFV-specific antibodies detected in serum of pigs immunized with BA71 $\triangle \mathrm{CD} 2 f(\mathrm{~A})$, BA71 $\triangle C D 2 E P 153 R(B)$ and BA71 $\triangle$ CD2DP96R (C), before and after Georgia2007/1 challenge. Individual ELISA optical density (OD) values are shown for each immunization group. Average and standard deviation OD values obtained from the control group are also shown in each figure panel. 


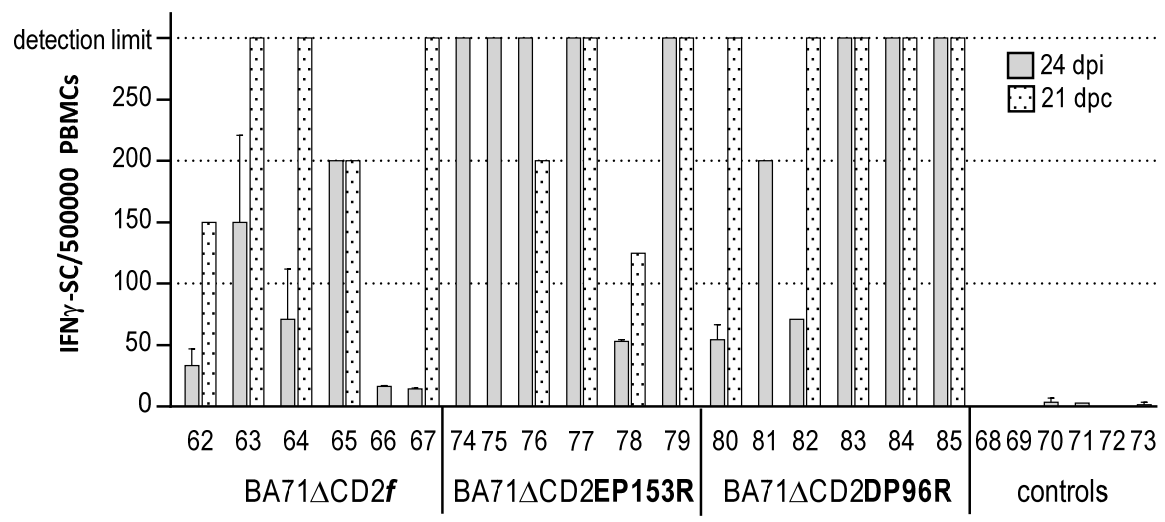

Figure 8. IFN $\gamma$-secreting specific T cells found in peripheral blood mononuclear cells (PBMCs) in vitro. Any sample scoring $\geq 300$ spots $/ 500,000$ PBMCs received a score of 300 , which was considered the limit of our assay resolution.

The ELISPOT data (Figure 8) confirmed the successful immunization of most of the animals, albeit that again, no correlation was observed between the number of ASFVspecific $\mathrm{T}$ cells present in blood and protection (confirming previous results). Thus, pigs 74 , 75 and 81 were good responders and died after Georgia2007/1 challenge, while several survivors showed low responses at the time of challenge.

In conclusion, deletion mutants of the attenuated recombinant ASF virus, BA71 $\triangle \mathrm{CD} 2$, decrease vaccine efficacy and do not increase its safety. The fine equilibrium existing between live attenuated ASFV vaccine replication, safety and efficacy requires a more profound study and might provide key lessons for the future.

Author Contributions: F.R. coordinated and edited the text writing and together with S.P.-P., D.P.G., M.V.B., N.A., J.A. and M.L.S. led the collaboration between the three institutions that participated in the present work. This work forms part of the thesis work of E.L., finished last year under the coordination of S.P.-P. and F.R. at IRTA-CReSA, Barcelona. E.L. prepared the first version of the paper and the figures here presented. F.A., S.P.-P., D.P.G. and M.V.B. coordinated the experimental work at IRTA-CReSA and USDA, respectively, and E.L., L.B.-C., J.Z., U.A., N.A., E.R.-M., E.V., M.M. and M.J.N. performed all the analytical work. All authors contributed to the writing and revised the submitted version of the manuscript. All authors have read and agreed to the published version of the manuscript.

Funding: This work was funded by the Ministerio de Ciencia, Innovación y Universidades from the Spanish Government (grant reference: AGL2016-78160-C2-1-R) with additional support from Huvepharma and CERCA from Generalitat de Catalunya.

Institutional Review Board Statement: Animal experiments were conducted according to animal welfare ethics and protocols approved by the Ethics Commission in Animal Experimentation of the Generalitat de Catalunya (code CEA-OH/9212/2, in accordance to the European (Directive 2010/63/EU) and Spanish (Real Decreto 53/2013) regulations under the supervision of the IRTA's Ethical and Animal Welfare Committee.

Data Availability Statement: The data that support the findings of this study are available from the corresponding author upon reasonable request.

Acknowledgments: We thank all the personnel in charge of field studies and BSL3 facilities at IRTACReSA for their continuous help and Kevin Dalton for final editing of the manuscript. Finally, we thank RLASB-ICTS and RISA from the Spanish Government and Global Alliance for Research on African swine fever (GARA) and World Organization for Animal Health (OIE) for their contribution.

Conflicts of Interest: No conflicts of interest to declare. 


\section{References}

1. Sánchez-Cordón, P.J.; Montoya, M.; Reis, A.L.; Dixon, L.K. African swine fever: A re-emerging viral disease threatening the global pig industry. Vet. J. 2018, 233, 41-48. [CrossRef] [PubMed]

2. Blome, S.; Gabriel, C.; Beer, M. Modern adjuvants do not enhance the efficacy of an inactivated African swine fever virus vaccine preparation. Vaccine 2014, 32, 3879-3882. [CrossRef]

3. Bosch-Camós, L.; López, E.; Rodriguez, F. African swine fever vaccines: A promising work still in progress. Porc. Health Manag. 2020, 6, 1-14. [CrossRef] [PubMed]

4. Onisk, D.; Borca, M.; Kutish, S.; Kramer, E.; Irusta, P.; Rock, D. Passively Transferred African Swine Fever Virus Antibodies Protect Swine against Lethal Infection. Virology 1994, 198, 350-354. [CrossRef] [PubMed]

5. Oura, C.A.L.; Denyer, M.S.; Takamatsu, H.; Parkhouse, M. In vivo depletion of CD8+ T lymphocytes abrogates protective immunity to African swine fever virus. J. Gen. Virol. 2005, 86, 2445-2450. [CrossRef]

6. O’Donnell, V.; Holinka, L.G.; Gladue, D.; Sanford, B.; Krug, P.W.; Lu, X.; Arzt, J.; Reese, B.; Carrillo, C.; Risatti, G.R.; et al. African Swine Fever Virus Georgia Isolate Harboring Deletions of MGF360 and MGF505 Genes Is Attenuated in Swine and Confers Protection against Challenge with Virulent Parental Virus. J. Virol. 2015, 89, 6048-6056. [CrossRef] [PubMed]

7. O’Donnell, V.; Holinka, L.G.; Krug, P.W.; Gladue, D.P.; Carlson, J.; Sanford, B.; Alfano, M.; Kramer, E.; Lu, Z.; Arzt, J. African Swine Fever Virus Georgia 2007 with a Deletion of Virulence-Associated Gene 9GL (B119L), when Administered at Low Doses, Leads to Virus Attenuation in Swine and Induces an Effective Protection against Ho-mologous Challenge. J. Virol. 2015, 89, 8556-8566. [CrossRef] [PubMed]

8. O'Donnell, V.; Risatti, G.R.; Holinka, L.G.; Krug, P.W.; Carlson, J.; Velazquez-Salinas, L.; Azzinaro, P.A.; Gladue, D.P.; Borca, M.V. Simultaneous Deletion of the 9GL and UK Genes from the African Swine Fever Virus Georgia 2007 Isolate Offers Increased Safety and Protection against Homologous Challenge. J. Virol. 2016, 91, e01760-16. [CrossRef]

9. Borca, M.V.; Ramirez-Medina, E.; Silva, E.; Vuono, E.; Rai, A.; Pruitt, S.; Holinka, L.G.; Velazquez-Salinas, L.; Zhu, J.; Gladue, D.P. Development of a highly effective African swine fever virus vaccine by deletion of the I177L gene results in sterile immunity against the current epidemic Eurasia strain. J. Virol. 2020, 94, e02017-19. [CrossRef]

10. Chen, W.; Zhao, D.; He, X.; Liu, R.; Wang, Z.; Zhang, X.; Li, F.; Shan, D.; Chen, H.; Zhang, J.; et al. A seven-gene-deleted African swine fever virus is safe and effective as a live attenuated vaccine in pigs. Sci. China Life Sci. 2020, 63, 623-634. [CrossRef]

11. Teklue, T.; Wang, T.; Luo, Y.; Hu, R.; Sun, Y.; Qiu, H.-J. Generation and Evaluation of an African Swine Fever Virus Mutant with Deletion of the CD2v and UK Genes. Vaccines 2020, 8, 763. [CrossRef]

12. Monteagudo, P.L.; Lacasta, A.; López, E.; Bosch, L.; Collado, J.; Pina-Pedrero, S.; Correa-Fiz, F.; Accensi, F.; Navas, M.J.; Vidal, E.; et al. BA71 $\triangle$ CD2: A New Recombinant Live Attenuated African Swine Fever Virus with Cross-Protective Capabilities. J. Virol. 2017, 91. [CrossRef]

13. Hurtado, C.; Bustos, M.J.; Granja, A.G.; De León, P.; Sabina, P.; López-Viñas, E.; Gómez-Puertas, P.; Revilla, Y.; Carrascosa, A.L. The African swine fever virus lectin EP153R modulates the surface membrane expression of MHC class I antigens. Arch. Virol. 2010, 156, 219-234. [CrossRef] [PubMed]

14. O'Donnell, V.; Holinka, L.G.; Sanford, B.; Krug, P.W.; Carlson, J.; Pacheco, J.M.; Reese, B.; Risatti, G.R.; Gladue, D.P.; Borca, M.V. African swine fever virus Georgia isolate harboring deletions of 9GL and MGF360/505 genes is highly attenuated in swine but does not confer protection against parental virus challenge. Virus Res. 2016, 221, 8-14. [CrossRef] [PubMed]

15. Gallardo, C.; Sánchez, E.G.; Pérez-Núñez, D.; Nogal, M.; de Leon, P.; Carrascosa, Á.L.; Nieto, R.; Soler, A.; Arias, M.L.; Revilla, Y. African swine fever virus (ASFV) protection mediated by NH/P68 and NH/P68 recombinant live-attenuated viruses. Vaccine 2018, 36, 2694-2704. [CrossRef] [PubMed]

16. Reis, A.L.; Goatley, L.C.; Jabbar, T.; Lopez, E.; Rathakrishnan, A.; Dixon, L.K. Deletion of the Gene for the Type I Interferon Inhibitor I329L from the Attenuated African Swine Fever Virus OURT88/3 Strain Reduces Protection Induced in Pigs. Vaccines 2020, 8, 262. [CrossRef] [PubMed]

17. Gladue, D.P.; O’Donnell, V.; Ramirez-Medina, E.; Rai, A.; Pruitt, S.; Vuono, E.A.; Silva, E.; Velazquez-Salinas, L.; Borca, M.V. Deletion of CD2-Like (CD2v) and C-Type Lectin-Like (EP153R) Genes from African Swine Fever Virus Georgia-9GL Abrogates Its Effec-tiveness as an Experimental Vaccine. Viruses 2020, 12, 1185. [CrossRef]

18. Sanford, B.; Holinka, L.; O’Donnell, V.; Krug, P.; Carlson, J.; Alfano, M.; Carrillo, C.; Wu, P.; Lowe, A.; Risatti, G.; et al. Deletion of the thymidine kinase gene induces complete attenuation of the Georgia isolate of African swine fever virus. Virus Res. 2016, $213,165-171$. [CrossRef]

19. Borca, M.V.; O’Donnell, V.; Holinka, L.G.; Sanford, B.; Azzinaro, P.A.; Risatti, G.R.; Gladue, D.P. Development of a fluorescent ASFV strain that retains the ability to cause disease in swine. Sci. Rep. 2017, 7, 46747. [CrossRef]

20. Lacasta, A.; Ballester, M.; Monteagudo, P.L.; Rodriguez, J.M.; Salas, M.L.; Accensi, F.; Pina-Pedrero, S.; Bensaid, A.; Argilaguet, J.; Lopez-Soria, S.; et al. Expression Library Immunization Can Confer Protection against Lethal Challenge with African Swine Fever Virus. J. Virol. 2014, 88, 13322-13332. [CrossRef] 
21. Galindo-Cardiel, I.; Ballester, M.; Solanes, D.; Nofrarías, M.; López-Soria, S.; Argilaguet, J.M.; Lacasta, A.; Accensi, F.; Rodríguez, F.; Segalés, J. Standardization of pathological investigations in the framework of experimental ASFV infections. Virus Res. 2013, 173, 180-190. [CrossRef] [PubMed]

22. Argilaguet, J.; Pérez-Martín, E.; Gallardo, C.; Salguero, F.J.; Borrego, B.; Lacasta, A.; Accensi, F.; Díaz, I.; Nofrarías, M.; Pujols, J.; et al. Enhancing DNA immunization by targeting ASFV antigens to SLA-II bearing cells. Vaccine 2011, 29, $5379-5385$. [CrossRef] [PubMed] 